\title{
La configuración de la convivencia y la paz en la literatura
}

\section{El camino investigativo de la convivencia y la paz}

La búsqueda de evidencias y resultados de investigación en el ámbito de la convivencia y la paz arrojó algunos resultados muy relevantes que sirven de base para el proceso de indagación que desarrolló el estudio. Con el fin de reconocer avances importantes en esta materia se inició el trabajo en Europa, y puntualmente en España.

En tierra cantábrica, Azcune (2013), apoyado por la Universidad Internacional de la Rioja (España), confirma la importancia del tema investigado, ya que este se identifica con la educación para la paz. Educación indispensable para afrontar los retos de la sociedad actual, puesto que con ella se fomenta una formación integral de la persona en el marco de una cultura de paz.

Pantoja y Díaz (2009), en la Universidad de Jaén, España, teniendo en cuenta la teoría freireana, desarrolló su investigación en torno a "los proyectos" tomando la escuela como espacio de paz, aportando una propuesta integral para la mejora de la convivencia en el ámbito escolar. Esta, a diferencia de Azcune, estudia el tipo de estrategia pedagógica del educando recepcionista de la misma, como medida para 
determinar la idoneidad del proceso "Plan Andaluz Cultura de Paz" en la provincia de Jaén. Se trata de un estudio donde diversos actores educativos califican políticas de educación estatal (pp. 121-137).

En su investigación sobre convivencia y paz, Caballero (2010), con la Universidad de la Nueva Granada (España), se centra en conocer algunas particularidades de prácticas educativas enfocadas en la promoción de la paz y la convivencia en el ámbito escolar, con la finalidad de continuar fortaleciendo este tópico (p. 154).

Asimismo, Muñoz y Molina (2010), en su trabajo apoyado por la Universidad de Granada, profundizan en los significados de la cultura de paz, entendida como "todas aquellas acciones que promocionen los mayores equilibrios posibles" (p. 44).

Por otro lado, Dopico (2011) despliega una investigación práctica para describir esta conflictividad, indagando sobre la existencia del conflicto en los centros educativos y cómo tratar de delimitarlo, señalando en qué niveles o ciclos educativos, y por lo tanto edades, se produce con más insistencia esta problemática.

Similar es el estudio en España por parte de García (2012), en el que se reconoce que ante la creciente presencia en escenarios socioeducativos de la figura profesional del mediador en los dos ámbitos principales relacionados con la educación, deben identificarse los rasgos característicos de cada uno de ellos, lo que no es óbice para reconocer diferencias en la definición de estos dos modelos de mediación.

Pero también la figura de la mediación ha sido el interés de Alzate, Fernández y Merino (2013), quienes postulan una interesante propuesta de que los centros de mediación comunitaria deben adaptarse a la complejidad de los conflictos del mundo actual y responder a ellos con variados enfoques y metodologías: asesoramiento en resolución de conflictos, mediación, técnicas de intervención con grandes grupos, entre otras (p. 179). Este estudio de carácter comunitario muestra en su contenido la necesidad de formar para la resolución pacífica de conflictos desde los institutos educativos.

Igualmente, se destaca el estudio de Pariente y Perochena (2013) en España, donde se presenta una propuesta didáctica para el desarrollo de valores en estudiantes de Educación Secundaria Obligatoria (ESO). En ella se utilizaron las Tecnologías para el Aprendizaje y el 
Conocimiento (TAC) como recurso en un programa diseñado e implementado por el equipo investigador en un centro escolar y evaluado mediante diseño cuasi-experimental con medidas de los "valores socio-personales para la convivencia” prepostest (p. 195).

Referente a esta situación, Caballero (2010) realizó un trabajo investigativo centrándose en la convivencia escolar enmarcado en la línea de educación para la paz. La finalidad de este fue conocer algunas peculiaridades de prácticas educativas que fomentan la paz y la convivencia en el ámbito escolar (p. 120).

Dado que la paz surge de la buena convivencia, Acosta (citado en Caballero, 2010) plantea que los pilares en los que se fundamenta una buena convivencia son: la cohesión del grupo con el que se quiere realizar cualquier actuación, la gestión democrática de normas, el trabajo positivo sobre regulación de los conflictos, la educación emocional y la educación en valores. El resultado del afianzamiento de todos estos aspectos demostró un buen desarrollo de las habilidades socioemocionales (p. 161).

Asimismo, Caballero (2010) considera que los problemas de convivencia no dejan de ser problemas de valores sociales, en los que la institución escolar y la acción pedagógica de los profesionales pueden jugar un papel fundamental, pero no son ni los únicos ni los principales. El profesorado considera de importancia capital la participación familiar, sin cuyo apoyo difícilmente se conseguirá educar en una cultura de paz (p. 166).

En la investigación de Pantoja y Díaz (2009) se descubrió a través de una metodología descriptiva que los proyectos integrales promueven el buen trato como medidas de prevención de la violencia en la comunidad autónoma de Andalucía, acompañado de un marco teórico de cultura de paz mediante el proyecto "Escuela: Espacio de Paz" (p. 121).

En este estudio de Pantoja y Díaz, se pretendió determinar la idoneidad de la ejecución de los proyectos a nivel educativo en los centros de la provincia de Jaén, que se vienen ejecutando para mejorar la convivencia escolar. Con los resultados obtenidos en esta investigación se pudo determinar que la tarea propuesta a nivel mundial es asumir que el conflicto hace parte de la sociedad y que la humanidad debe aprender a conocer las estrategias para mejorar la convivencia 
pacífica. Como resultado, las investigaciones demuestran que los centros educativos implicados en el estudio dejan ver que los currículos, la participación de los distintos sectores de la comunidad educativa y de las organizaciones estatales, hacen parte del trabajo realizado en los proyectos como medida preventiva para mejorar la convivencia.

En este orden de ideas, tanto Pantoja y Díaz (2009) como Caballero (2010), coinciden en que la educación en valores como medida preventiva para mejorar la convivencia son tarea de cada uno de los distintos sectores de la comunidad educativa y de las organizaciones estatales para hacer un equipo de trabajo conjunto, que establezca directrices y programas para la resolución pacífica de los conflictos.

Otro antecedente se encuentra referenciado en la necesidad de educar en la convivencia, según lo plantea Díaz de Cerio (1998), cuando manifiesta que "para construir un camino hay que moverse entre dos puntos: el punto de partida y la meta a la que se quiere llegar. Antes de diseñar el trayecto, es preciso hacerse dos preguntas elementales: ‘¿dónde estamos?' y ‘‘a dónde queremos ir?’” (p. 19).

Este investigador explica que "lo mismo pasa con la Educación para la Convivencia Pacífica”. Agrega que antes de dar el primer paso, hay que enfrentarse a este tipo de preguntas: “¿cómo es la convivencia en nuestra sociedad?” y “qqué paz queremos para nuestros alumnos?” (Díaz de Cerio, 1998, p. 19).

Para este autor, un tema o enseñanza clave para la vida es la paz o convivencia pacífica. "El ser humano, social por naturaleza, necesita aprender a relacionarse con los demás. Se trata de una necesidad básica”. El éxito de la vida radica en la consecución de la armonía consigo mismo, con los demás y con su medio ambiente: "Vivimos, además, en una época bastante conflictiva, violenta, intolerante, injusta e inestable, con frecuentes y graves problemas de convivencia. La situación actual del mundo reclama una actuación escolar en este punto" (Díaz de Cerio, 1998, p. 19).

Este autor considera que "nos urge así la aplicación de una enseñanza que desarrolle, en nuestros alumnos, las actitudes y conductas más coherentes con la justicia, el respeto, la tolerancia, el diálogo y la resolución no violenta de los conflictos”. Díaz señala que: 
[...] esta preocupación por la educación para la paz es anterior a la Reforma. Nace como consecuencia de la Primera Guerra Mundial (educación para la comprensión internacional). Se caracteriza por su sensibilidad a la no-violencia y la formación de las libertades (educación para la autonomía, la resolución de los conflictos de forma no violenta y la desobediencia ante las injusticias). A partir de los 60, la educación para la paz pone un énfasis especial en el desarrollo de los países del Tercer Mundo. (M.E.C., 1992, p. 13)

Por su parte, García (1998), en su trabajo Un aula pacífica para una cultura de paz, sostiene que "tenemos que desarmar la historia. Hemos aprendido y hemos enseñado la historia del poder. No la del saber. La de la guerra, no la de la cultura”. Asimismo, García expresa que
[...] la Historia enseñada ha sido una Historia jalonada de acon- tecimientos bélicos, con el fragor de las armas como única banda sonora". Y complementa que "tenemos, pues, que cambiar. Sí, te- nemos que aprender a pagar el precio de la paz, como hemos te- nido que pagar el precio de la guerra. (p. 2)

Para ello, García sugiere que "Sería útil y necesario establecer nuevas prioridades en la enseñanza de las ciencias sociales” (Mayor Zaragoza, 1997, citado en García, 1998).

El autor manifiesta su visión en propuestas como "un aula pacífica para una cultura de paz" y propone "que los alumnos aprendan a solucionar los conflictos no por la violencia y guerra sino mediante una serie de técnicas y estrategias preventivas y de tratamiento que conduzcan a la paz". Añade que no duda "que surjan en las aulas y centros escolares conflictos culturales, ideológicos, raciales, sentimentales, (...) sino lo que interesa es que los alumnos aprendan a dar soluciones pacíficas en lugar de acudir a la agresividad, agresión física, armas, maltratos” (p. 3). En el mismo sentido en que Chaux (2005) reseña que:

Varios estudios adelantados en otras latitudes del mundo han hallado que la mayoría de, los(as) niños(as) al finalizar la infancia y al comenzar la adolescencia, si no han recibido entrenamiento en 
resolución de conflictos, responden a estos con sus pares amigos(as) o compañeros(as), ya sea evitando a las otras personas, o imponiendo sus objetivos sin tener en cuenta cómo al hacerlo puedan estar afectando negativamente sus relaciones. (p. 44)

El estudio de Chaux, evidenció que

[...] aproximadamente uno de cada tres estudiantes en estos colegios (de Bogotá) tiene una pelea física cada semana. En particular, esta frecuencia en agresión física es mucho más alta que aquella mostrada en otros estudios similares realizados con niños(as) de clase media en los Estados Unidos. (p. 44)

En el mismo campo, Aznar, Cáceres e Hinojo (2008) divulgaron que "La Asociación pro derechos del niño, Prodeni, llevó a cabo en 2005, una investigación sobre violencia escolar en los Institutos de Secundaria en el Puerto de Santa María (Cádiz)". Los autores destacaron cómo "los datos más relevantes arrojaron resultados como que casi un $30 \%$ de alumnos, de una muestra de 2000 adolescentes, reconoce haber pegado a un compañero y un $7 \%$, reconoce haber agredido a un profesor" (p. 1).

Estos datos reflejan, de acuerdo con José Luis Calvo Casal (Vicepresidente nacional y fundador de Prodeni), que "la violencia escolar es un problema real al que las administraciones no le están prestando la atención necesaria..." (Aznar et al., 2008). Según esta investigación, "Las causas de este fenómeno están en la propia sociedad y el estilo de vida de hoy día” (Diario de Cádiz, 24 de julio de 2005, p. 2, citado en Aznar et al., 2008, p. 1).

Aznar et al. (2008) citan una de las investigaciones más recientes, protagonizadas por el Informe Cisneros VII (septiembre de 2005), centrado en el estudio de la violencia y el acoso escolar en alumnos de Primaria, Eso y Bachiller, coincide con los elevados porcentajes presentados anteriormente. Aznar et al. (2008) explican que:

Entre lo más destacado: Un $24 \%$ de los alumnos encuestados se encuentran en una situación técnica de acoso escolar o acoso 
psicológico en la escuela. Entre tanto, la tasa de acoso escolar por sexos es de $26,8 \%$ para los niños y de $21,1 \%$ para las niñas. Mientras que las conductas de desprecio y ridiculización, junto con las de hostigamiento verbal son las que provocan mayores índices de ideación suicida entre las víctimas. $(2008$, p. 1)

Estos datos revelados por Aznar et al. (2008), corroboran los hallazgos de Montoro (2008), quien sostiene que "se ha producido un claro desfase entre el papel tradicional que la escuela ha venido desempeñando y las demandas de la escuela de nuestros días". Agrega que "probablemente, uno de los cambios más significativos en los últimos años, ha sido el nivel de violencia que se viene generando en las aulas y que preocupa enormemente a todos aquellos que participan en los procesos educativos" (p. 102).

Su planteamiento coincide con (Gijón y Puig, 2010) cuando expone que "se ha hablado de crisis en la enseñanza, de decadencia de valores y de responsabilidades, de diferencia de criterios para abordar situaciones entre familias y escuela" (Montoro, 2008, p. 102).

A su turno, Caballero (2010), en una investigación apoyada por la Universidad de Granada (España), presentó “Convivencia escolar. Un estudio sobre buenas prácticas”, que tenía como objetivo general analizar experiencias en centros educativos que estando acogidos a la red de "Escuela: espacio de paz", han desarrollado un proyecto de convivencia de centro, para extraer conclusiones acerca de las actividades que se llevaban a cabo preferentemente en las tutorías, conocer las necesidades de los centros y así poder realizar propuestas a la administración educativa. Para este caso, los principales resultados y conclusiones fueron expuestos en recomendaciones dirigidas.

Se coincide con este estudio en que la extensión a los espacios comunitarios ha sido una de las fases más importantes para garantizar el éxito de los procesos de promoción de la cultura de paz en las instituciones, a través, por ejemplo, de tomar medidas de participación activa del estudiantado, además de otras medidas como la creación de protocolos de control de clase, la creación y establecimiento de estructuras funcionales como: el aula de convivencia, aula temporal de integración 
(ATI), aula temporal de atención lingüística (ATAL), reuniones periódicas informativas con la asociación de madres y padres y programas de absentismo, entre otras. Estas estrategias son eficaces para conseguir un buen clima de aula y de centro y, aunque son referentes a los proyectos investigativos adelantados por Caballero (2010), logran dimensionar la demanda de los espacios de encuentro y la implementación de modelos de ejercicio ciudadano en los planteles educativos (p. 2).

También en España, Álvarez-García et al. (2010) contemplan como objetivo principal analizar la relación entre fracaso escolar y violencia en los centros de educación secundaria, focalizando 1742 estudiantes de siete centros de Asturias. Los resultados muestran que el alumnado que ha repetido alguna vez curso percibe mayores niveles de violencia en su centro educativo que aquel que nunca ha repetido. Y esto es así para todas las variables dependientes evaluadas (p. 1).

Estos evidentes problemas de convivencia han sido intervenidos y por ello, Torrego (2010) busca exponer un proyecto más amplio de investigación sobre la innovación educativa en España. El estudio centra las conclusiones en el cruce entre dos elementos de interés: la mejora de la convivencia y la reflexión sobre aquellos principales factores potenciadores e inhibidores de la innovación en este centro educativo (p. 1).

Las investigaciones para validar estrategias de superación de los conflictos también fueron adelantadas por académicos como Valdemoros et al. (2011), quien direcciona su trabajo en pro de verificar la idoneidad del ocio físico-deportivo para el fomento de valores sociales dirigidos a optimizar la sociabilidad y la convivencia de los adolescentes, considerándose, asimismo, a la familia como agente cardinal de este proceso. Los resultados ratifican que el ocio físico deportivo es, a priori, un contexto axiológico neutro, que posee el potencial de fomentar tanto valores como contravalores; que la familia se constituye como un agente educativo fundamental susceptible de condicionar el hábito físico-deportivo del adolescente (p. 1).

Pero, además, en el afán de revisar la influencia de la práctica pedagógica en este segmento de la vida escolar como lo constituye la convivencia pacífica, se identificó un documento de Alemany et al. (2012), quienes examinaron las percepciones que observa el profesorado de primaria y secundaria sobre las situaciones conflictivas que 
se dan en su aula. El estudio pretendía conocer en qué medida se observan y padecen situaciones que afectan a la convivencia escolar, es decir, analizar cómo los docentes resuelven las situaciones conflictivas que se dan en su aula (p. 1).

La investigación de Alemany et al., podría complementarse con el trabajo de Gómez (2009), quien con su aporte, desarrolla una aproximación a la creación de un imaginario de la paz en las instituciones educativas para la convivencia humana desde una racionalidad comunicativa. Adicionalmente, brinda pautas para la postulación de estrategias pedagógicas que contribuyan permanentemente a una verdadera pertinencia social de su acción educativa desde y para la convivencia humana (p. 1).

A estas investigaciones sustentadas desde la práctica educativa se suman las de Romero y Caballero (2008), cuyo trabajo está enfocado a analizar las relaciones entre clima social de aula y clima general de la sociedad en la cual la institución educativa está inserta. Proponen una posibilidad metodológica que mejora el clima social, ofreciendo a profesorado y alumnado el ejercicio de un trabajo potencialmente transformador, que profundiza en los valores de una relación a su alrededor; bases estas de una relación democrática, y de un clima social de aula positivo (p. 29).

Desde una perspectiva inclusiva de prácticas pedagógicas de convivencia pacífica en los centros escolares, Zaitegi (2010) plantea la necesidad de promover la convivencia en los centros escolares en España (p. 93). Pero también la acción pedagógica se prioriza como estrategia para disminuir los niveles de conflicto, así lo plantean GarcíaHierro y Cubo (2009), de la Asociación Universitaria de Formación del Profesorado de España, quienes se interesaron por trabajar la temática, delimitándola para replantear las estrategias de enseñanza y aprendizaje sobre valores y convivencia, al diagnosticar en primera instancia el clima social de las instituciones objetos de estudio, particularmente en un grupo de alumnos/as. 


\section{Los orígenes de la paz ${ }^{1}$}

El origen etimológico de la palabra "paz” es grecolatino: viene del griego eirene y del romano pax. Eirene es sinónimo de armonía (bomonoia), definida como un estado singularmente armónico caracterizado por la ausencia de hostilidad y de conflicto violento y abierto, referenciando a la unidad interior y social. También se relaciona con la labor estoica de la búsqueda eterna de tranquilidad interior y armonía mental y espiritual. Un tercer significado que le dan los griegos se relaciona con el ser, como una oposición al conflicto violento y bélico: "un término negativo definido como la ausencia de conflicto" (Lederach, 2000, p. 17).

Para los romanos, la pax tiene un significado parecido al propuesto por los griegos: la paz indica una relación legal y recíproca entre dos partidos, la preservación del orden establecido. La paz es ley, orden y ausencia de conflicto y la ordena el imperio romano mediante su aparato militar. Sostiene Lederach (2000) que, en el marco de la filosofía imperialista romana, es "ausencia de violencia según la ley", pero no en el sentido de justicia, prosperidad, reciprocidad o igualdad para todos, sino en el sentido de mantener el orden interior como preparación bélico-militar para la conquista o la defensa del imperio. En este mismo marco, tiene una segunda acepción: es universal y su centro es el Estado-nación de Occidente. Sin embargo, estas dos tendencias derivan en un mismo significado negativo: la paz puede entenderse como lo opuesto a la guerra o la ausencia de violencia.

Pero el concepto problemático dado en el acontecimiento, según palabras de Deleuze y Guattari (1999), no se agota en comprensiones históricas y etimológicas. Los marcos filosóficos y culturales también dejan su impronta en el concepto: es el caso del concepto "paz” para la cultura oriental, que se interioriza en la persona. Afirma Lederach

1 Este apartado conceptual se originó en la investigación titulada " ¿Y si no me reconozco en él, quién soy? Representaciones sociales de estudiantes universitarios sobre el papel de la universidad en la creación de cultura de paz" (2015), financiada por el Fondo de Investigaciones de la Universidad Francisco de Paula Santander de Cúcuta (Colombia) (Código: 043-2015). 
(2000) que la paz, llamada shandi por los hindúes y abimsa por los jainistas, es un estado que incluye el buen ordenamiento de la mente y el deber personal y socio-político de respetar a todo ser.

Para los hebreos, el término shalom, que según Lederach (2000) corresponde a la "paz" de los occidentales, inicialmente se relaciona con la prosperidad y el bienestar material en el marco de un contexto de relaciones: primero está la relación con Dios a través del pacto, y luego están las relaciones entre el pueblo. El shalom depende de la justicia y de la calidad de estas relaciones expresadas en dos niveles principales: en primer lugar, el nivel interpersonal o la forma de llevarse con los demás (justicia), y, en segundo lugar, el nivel nacional, que se refiere a la estructura socioeconómica que regula las relaciones del pueblo (jubileo).

Otra concepción interesante es la visión de paz expresada en el cristianismo primitivo, opuesta de forma patente a la concepción asumida por dicha religión después de la conversión de Constantino. El concepto original de paz cristiano también se sitúa en el plano del establecido con Jesús, manifestado en las relaciones interhumanas. El testimonio y la vida del Mesías se expresa en el amor y entrega por el prójimo: es la paz en el sentido de "ágape”, amor de entrega al prójimo, de sacrificio, de buena voluntad (Lederach, 2000, p. 29).

Estas aproximaciones permiten un primer acercamiento: la paz es un concepto problemático y complejo que mantiene una telaraña conceptual con otros conceptos como armonía, justicia social, bienestar, relaciones justas, tranquilidad interior, estado bien ordenado de la mente, entre otros. En el mismo sentido, Benítez (2009) define la paz como un proceso dinámico y cambiante, no como una referencia estática e inmóvil; es un proceso imperfecto, inacabado e incompleto, que coexiste con el conflicto y con sus manifestaciones; un proceso construido de forma colectiva y reconocido en la cotidianidad; una búsqueda del bienestar de las personas y la satisfacción de sus necesidades; una estructura social de amplia justicia y reducida violencia, que apuesta por la equidad y reciprocidad en las relaciones; un proceso que afecta todas las dimensiones de la vida: no se reduce únicamente a la dimensión internacional o de estado (pp. 148-149). 
Vincenc Fisas (1998), en el texto titulado "Cultura de paz y gestión de conflictos”, identifica varias concepciones de paz:

- Paz como ausencia de guerra: se centra en los conflictos violentos entre Estados.

- Paz como equilibrio de fuerzas en el sistema internacional: un equilibro dinámico de factores políticos, sociales, culturales y tecnológicos. La guerra se produce cuando este se rompe.

- Paz negativa: la ausencia de guerra.

- Paz positiva: se opone a la violencia estructural. Es su ausencia u oposición.

- Paz feminista: la paz no solo incluye la abolición de la violencia organizada a nivel macro; también a nivel micro, como las violaciones en la guerra o en el hogar y la violencia intrafamiliar. El concepto de violencia estructural se expandió de forma similar para incluir las estructuras a nivel interpersonal, daños y discriminaciones contra individuos y grupos. La guerra, entendida como forma de resolver los conflictos, es considerada una manera masculina de afrontar el conflicto.

- Paz holística: concede un alto valor a las relaciones de los seres humanos con el ambiente y su nivel personal e interno. Incluye aspectos espirituales.

Mosquera (2002) propone cuatro acepciones del concepto "paz”: la primera concibe la paz como una negociación entre Estados; en caso de guerra, se logra y garantiza gracias a los buenos oficios de la diplomacia internacional. La segunda acepción asocia la paz con los diálogos entre los grupos armados y el Estado; se refiere a todas aquellas búsquedas de salidas políticas negociadas en situaciones de guerra civil. La tercera se refiere a la "diplomacia paralela" de las ONG internacionales, que fungen como salvaguardas y veedoras de la paz en el mundo, tratando situaciones problemáticas de orden social que afectan el interés global. La cuarta acepción de la paz para Mosquera es la difundida a través del movimiento conocido como Nueva Era, por medio de narrativas que la describen como un estado intimista. 


\section{Las múltiples miradas a la paz}

Entendiendo que la paz tiene implicaciones sociales, económicas, políticas, religiosas y técnico-militares, como realidad multifacética, la paz es un producto cultural susceptible de aprenderse. La paz como concepto puede entenderse como vaga, emocional y manipulable, pero a la vez, suscita en todos un ideal, una ilusión y el presentimiento de una condición de vida y convivencia deseable y digna de nuestro esfuerzo y entrega (Lederach, 2008). Asumir la paz como acontecimiento implica no reducirla a regularidades subyacentes ni a un caos arbitrario, sino comprender el concepto como "creador de sentido" en su condición de devenir.

Jares (1999) cita un conjunto de autores clásicos que ayudan al seguimiento histórico del concepto tradicional de paz: Galtung (1985, 1996b), Arenal (1989), Lederach (1984, 2000 y 2008) y Curle (1978). En síntesis, estos autores plantean una distinción entre la concepción tradicional y la concepción positiva de paz. En el primer caso, se refieren a un concepto negativo, en el cual la paz es toda ausencia de conflicto; en el segundo caso, la paz ya no es solo lo contrario de la guerra sino la antítesis de la violencia.

Para otros autores (citados en Jares, 1999) como Betty Reardom (1978), la paz es el conjunto de las relaciones humanas, en el cual la justicia puede conseguirse sin violencia. William Eckhardt (1986), por su parte, enfatiza sobre la necesidad de cambiar las relaciones de explotación hacia un clima de justicia para todos como factor para propiciar la paz. Naidu (1986) otorga a la paz cinco dimensiones: no violencia, justicia económica, igualdad social, libertad política y fraternidad psicológica. Veslemy Wiese (1977) estudia la paz como el resultado de la igualdad de los derechos de todos los miembros de un conglomerado social.

En el mismo sentido, Benítez (2009) define la paz como un proceso dinámico y cambiante, no como una referencia estática e inmóvil. Como un proceso imperfecto, inacabado e incompleto, que coexiste con el conflicto y con sus manifestaciones. Como un proceso que se reconoce y construye colectivamente en la cotidianidad. Como un camino de búsqueda de bienestar de las personas y satisfacción de sus 
necesidades. Como una estructura social de amplia justicia y reducida violencia, que apuesta por la equidad y reciprocidad en las relaciones. Como un proceso que afecta todas las dimensiones de la vida. No se reduce únicamente a la dimensión internacional o de Estado.

$\mathrm{Al}$ abordar la paz, se debe considerar que esta es concebida con diferentes particularidades, tal es el caso de la paz cultural y la paz imperfecta. La primera es presentada por Muñoz con una concepción sobre la cual gira, en gran parte, la propuesta pedagógica característica de la experiencia del Bachillerato Pacicultor: se trata de la llamada "paz cultural”, definida como una respuesta de los humanos a los desafíos del entorno en el que habitan y, en consecuencia, las relaciones establecidas dentro de la especie. Es una respuesta que busca mayor grado de organización, de equilibrio y armonía en la especie y con su medio, ya que se retroalimentan entre sí. En esta perspectiva la paz significa "alcanzar el máximo de equilibrio interno y, en esa medida, el menor grado de entropía, de desorden de la energía, de los recursos” (Muñoz y Molina, 2010). Al hablar de paz como cultura, nos referimos al acercamiento a una perspectiva que permita construir una idea de paz activa, dinámica y realizable, que nos permita actuar desde nosotros mismos como sujetos sociales; una paz que es camino, método, mentalidad, pedagogía y paradigma.

En el año de 1999, la Unesco promueve el documento titulado $L a$ declaración y programa de acción sobre una cultura de paz. En este se define la cultura de paz como el conjunto de valores, actitudes, tradiciones, comportamientos y estilos de vida basados en el respeto a la vida, el fin de la violencia y la promoción y práctica de la no violencia por medio de la educación, el diálogo y la cooperación. El respeto pleno de los principios de soberanía, integridad territorial e independencia política de los Estados y de no injerencia en los asuntos internos; los derechos humanos y las libertades fundamentales y su promoción, los cuales incluyen la igualdad de derechos y oportunidades de mujeres y hombres, el derecho a la libertad de expresión, opinión e información. El compromiso con el arreglo pacífico de los conflictos. Los esfuerzos para satisfacer las necesidades de desarrollo y protección del medio ambiente de las generaciones presentes y futuras. La adhesión a los principios de libertad, justicia, democracia, 
tolerancia, solidaridad, cooperación, pluralismo, diversidad cultural, diálogo y entendimiento a todos los niveles de la sociedad y entre naciones (Organización de las Naciones Unidas, Resolución A/RES/53/243, p. 7, 1999).

La segunda concepción es la de Muñoz (citado en Grabe, 2006), quien propone una nueva concepción al plantear la "paz imperfecta". Se usa este término para hablar de realidades en las cuales ocurren conflictos pacíficos y violentos, donde es posible lograr la paz mediante la imperfección de las acciones humanas. Es una paz más cercana a la naturaleza humana, que hace posible converger los aspectos positivos y negativos, los aciertos y los errores. Acepta el conflicto, es "una paz movilizadora, integradora, constructiva y construible, donde logremos conciliar aspiraciones y limitaciones, sueños y realidades" (Grabe, 2006, p. 10).

Siguiendo a Muñoz y Molina (2010), este enfoque permite:

- Una compresión holística y no fragmentada de la paz. Una ruta para acceder a la complejidad de su estudio. Una mayor promoción de valores, actitudes e ideas múltiples de paz.

- Un cambio de percepción por cuanto asume la paz cotidiana que caracteriza al ser humano, lo cual genera esperanzas y lo moviliza a integrar nuevas experiencias.

- Acaba con la dicotomía de "buenos" y "malos" permitiendo reconocer en los actores del conflicto valores, vivencias y actitudes de paz.

Con Lederach $(2000,2008)$ se asumen cinco elementos necesarios para la construcción del concepto de paz: primero, se reconoce que es un valor y un ideal multidimensional. Segundo, es imprescindible concretar una concepción amplia de la violencia que abarque tanto las prácticas violentas directas de carácter político, militar, social y cultural, como las prácticas violentas estructurales como el racismo, el hambre, la marginación, etc. Tercero, es importante asumir la paz como una forma de reducir la violencia y elevar la justicia: a menos violencia más justicia. Cuarto, la paz es un proceso, y por lo tanto es 
dinámica. Finalmente, la paz es la ausencia de condiciones no deseadas (guerras, marginación, hambre), pero también es la presencia de condiciones y circunstancias deseadas de colaboración mutua, entendimiento y confianza (Lederach, 2000).

En síntesis, la paz es un concepto complejo y rico en sus múltiples acepciones. Como acontecimiento se inscribe en los propios imaginarios de una sociedad determinada, que asume desde los usos individuales y colectivos las costumbres y la cultura, sus maneras de entender y construir las "paces". No es solo ausencia de guerra, también construye una nueva cultura desde el conflicto, sin olvidar que su naturaleza humana la hace imperfecta y parte de las acciones cotidianas en que se mueve todo ser humano.

\section{Educación para la paz}

La cultura y la educación para la paz son ideales tan antiguos como la concepción de la guerra misma, ambos fenómenos fundados en la necesidad humana de convivir juntos y el derecho. El hombre se desarrolla como tal gracias a su naturaleza social, y eso depende de la calidad del sistema de relaciones sociales y prácticas socializadoras de su medio circundante. Es precisamente en el marco de esta convivencia y las relaciones interpersonales que establece, que el ser humano recibe toda la cultura material y espiritual de la sociedad, necesaria para su adaptación al medio natural y social, y su interacción activa y dinámica con el mismo.

Desafortunadamente, como afirman Pascual y Yudkin (2004):

[...] este amplio legado ha sido relegado y ocultado, ya que la historia siempre se ha escrito desde la perspectiva de los guerreros y poderosos, razón por la cual, se hace necesario en la actualidad, analizar la historia desde la perspectiva creadora, no desde las guerras y el poder de los vencedores.

Los antecedentes más remotos de la educación para la paz se pueden encontrar en el siglo vi a.C. en la tradición oriental, con Majavira, 
fundador del jainismo, quien preconiza el ahimsa (no violencia) como el principal valor educativo del hombre. Posteriormente Buda unifica los conceptos de piedad y ahimsa hacia todos los seres como elementos sustanciales de vocación filosófica, religiosa y educativa. Jesucristo constituye otro antecedente importante, al promover una cultura de paz fundada en la no violencia, la justicia, la vida en comunidad y el amor al prójimo a través de su práctica cotidiana. Más adelante, Erasmo de Rotterdam y Juan Luis Vives defienden en sus tesis una especie de "pacifismo educativo neocristiano". Otro heredero de la tradición no violenta es Tolstói, con su rechazo a todo tipo de violencia e intervención a la hora de educar. Finalmente, Tagore y Gandhi proponen como principios de toda educación el contacto con la naturaleza, la armonía del espíritu y la educación para la vida.

Jares (2001) propone en su texto "Educación para la paz: su teoría y su práctica”, cuatro momentos históricos del desarrollo de la educación para la paz llamados "olas". La primera ola se enmarca en el desarrollo de la llamada Escuela Nueva. La segunda el nacimiento y desarrollo posterior de la Unesco. La tercera ola se caracteriza por los aportes invaluables de la no violencia, y la última correspondería a lo que el autor llama "la investigación para la paz".

A inicios del pasado siglo, en el contexto de la Primera Guerra Mundial, el movimiento de la Escuela Nueva señaló la necesidad de que la educación contribuyera al entendimiento entre las naciones y la superación de las hostilidades entre los países. Al concluir la contienda, nació una corriente educativa que se propuso concientizar sobre la necesidad de evitar la guerra, así como los ideales de internacionalismo y solidaridad. En los años treinta, estos esfuerzos se ven obstaculizados por el ascenso de las ideas totalitarias y xenofóbicas del fascismo y el nazismo.

Al concluir la Segunda Guerra Mundial, con la creación de las Naciones Unidas y específicamente de la Unesco con su proyecto de escuelas asociadas, se incorporó al proyecto educativo mundial la educación para el respeto a los derechos humanos y para el desarme. En los años sesenta surge la investigación por la paz como disciplina científica. En 1959 se funda el Instituto de Investigación Social y en 1964 la Asociación Internacional de Investigación por la Paz (IPRA), 
la cual difunde las ideas de Johan Galtung sobre violencia estructural, y las concepciones de Pablo Freire, que vinculan la educación con la emancipación de los pueblos, el desarrollo y la eliminación de las inequidades sociales.

A finales de los años ochenta, la educación para la paz se concentra en enfoques prácticos, tales como la familia, el aula, el barrio, así como otros grupos de pertenencia de los individuos, y en la convivencia en los espacios sociales más cercanos. Con ello se pretende formar a las personas en la construcción de una cultura de paz, mediante el actuar en estos niveles de base, a través del tratamiento no-violento de los conflictos.

Ya en los años noventa, la educación por la paz comienza a orientarse hacia un enfoque intercultural, debido a la globalización, a la formación de capacidades, habilidades y voluntad de convivencia armónica entre personas y grupos sociales de diferentes pueblos, con culturas y experiencias diversas en los individuos.

La Organización de las Naciones Unidas (ONU) declara el año 2000 como el Año Internacional de la Cultura de Paz, dando inicio al Decenio Internacional de la Cultura de Paz y No Violencia para la Niñez del Mundo (2001-2010). En este marco, un grupo de premios nobel de la paz inició una petición llamada Manifiesto 2000. Este documento, firmado por más de 75 millones de personas, constituyó un llamado a la humanidad a participar y hacerse responsable con su futuro, al comprometerse a:

- Respetar todas las vidas y la dignidad de cada persona sin discriminación ni prejuicios.

- Rechazar la violencia en todas sus formas practicando la no violencia activa.

- Liberar la generosidad a fin de terminar con la exclusión, la injusticia, la opresión política y económica.

- Escuchar para comprenderse al defender la libertad de expresión y la diversidad cultural, privilegiando siempre la escucha y el diálogo. 
- Preservar el planeta al promover un consumo responsable y un desarrollo que respete el equilibrio de los recursos naturales.

- Reinventar la solidaridad al propiciar la participación de todos y todas.

En la Declaración y el Programa de Acción para una Cultura de Paz, la Asamblea General de las Naciones Unidas reconoce que el desarrollo integral de una cultura de paz está estrechamente relacionado con la promoción de la solución pacífica de conflictos, el respeto mutuo, la comprensión y la cooperación internacional; el cumplimiento de las obligaciones y las leyes internacionales; la promoción de la democracia y el respeto a los derechos humanos y las libertades fundamentales; la estimulación del desarrollo de habilidades para el diálogo, la negociación, el consenso y la resolución pacífica de las diferencias en todas las personas; el fortalecimiento de las instituciones democráticas y la garantía de la participación de todos los ciudadanos en los procesos de desarrollo; la erradicación de la pobreza, el analfabetismo y las inequidades dentro de las naciones y, entre ellas; la promoción del desarrollo sostenible; la eliminación de todas las formas de discriminación, racismo y xenofobia, el entendimiento, la tolerancia y la solidaridad entre todas las civilizaciones, pueblos y culturas (1999).

La educación en todos los niveles es uno de los principales medios para construir una cultura de paz. Asimismo, los gobiernos, la sociedad civil, los medios masivos de comunicación, la familia, los maestros, los políticos, los grupos religiosos, los intelectuales, los científicos, los artistas, los trabajadores sociales, así como las organizaciones no gubernamentales, deben estar completamente implicados en la educación y promoción de una cultura de paz.

En consecuencia, como afirma Freire (1993), la educación para la paz implica desplazar la pedagogía autoritaria por una pedagogía de la pregunta, por una pedagogía problematizadora y democratizante del cuestionamiento, del atrevimiento, del disenso y de la audacia, por una pedagogía de la esperanza que, desde el imperativo existencial e histórico, contribuya a viabilizar nuestros sueños edificantes (p. 78). 
En ese sentido, la educación en y para la paz requiere la promoción de los derechos humanos, los valores asociados a ellos, y su respeto total; el compromiso con el derecho a una vida digna, la justicia social y la igualdad de oportunidades para todos; el rechazo a todas las manifestaciones de violencia, sean estructurales, sociales o interpersonales; la utilización de esta como estilo e instrumento para resolución de conflictos sociales intrapersonales, políticos y familiares; la lucha contra la corrupción y el caudillismo político; el fomento de valores como la generosidad, el diálogo, la escucha, el entendimiento, la participación y la solidaridad; la preservación de los recursos naturales y la estimulación de conocimientos, actitudes, valores y comportamientos favorables hacia el medio ambiente en todas sus dimensiones.

Desde la Cátedra Unesco de Educación para la Paz, de la Universidad de Puerto Rico, se proponen ciertas pautas para educar de manera efectiva para la paz en convivencia solidaria.

- Clima de seguridad, respeto y confianza: es indispensable articular un espacio educativo seguro, lo cual implica una visión de seguridad basada en la apertura, la prevención y la atención inmediata a los incidentes de violencia desde temprana edad. Se busca proporcionar un espacio para la no-violencia y la seguridad afectiva, construyendo un clima social de respeto y confianza, partiendo del trato afectuoso y las expectativas positivas para potenciar la autoestima de los integrantes de la comunidad escolar.

- Relaciones de apoyo con las familias y la comunidad: la escuela como agente socializador debe proveer una red de apoyo social al estudiante en relación con su familia y la comunidad. Al brindar acceso a los miembros de la comunidad inmediata, la escuela puede articular servicios que las familias necesiten para mejorar su calidad de vida. La familia y la comunidad deben verse como una oportunidad para el crecimiento mutuo y la convivencia. Para esto, se deben articular esfuerzos para prevenir la violencia en las familias y la ejercida con sus integrantes y las comunidades estudiantiles. Para lograr este 
objetivo, se debe conocer a la mayor cantidad de actores y entidades sociales -comunitarias o estatales- y aunar esfuerzos con ellos para alcanzar una convivencia pacífica.

- Educación emocional: la educación debe promover la competencia social y emocional de los estudiantes, mediante la integración de destrezas de vida a su experiencia educativa. En la educación emocional se enseña a comunicar sentimientos, experiencias y preocupaciones y se desarrolla la empatía por los sentimientos y situaciones de vida de los demás, un elemento indispensable para la vida de todo ser humano.

- Prácticas para el crecimiento, la apertura y la tolerancia: la experiencia educativa debe partir de la realidad de los estudiantes y propiciar el aprendizaje activo y con sentido. En otras palabras, debe ser un aprendizaje auténtico para el conocimiento y la transformación, que privilegie el aprendizaje cooperativo y colaborativo para aprender a vivir y trabajar con otros. Además, debe propiciar la adquisición de herramientas para comprender los prejuicios, apreciar la diversidad y practicar la tolerancia.

- Resolución no violenta de conflictos: es necesario asumir la “pedagogía del conflicto" en contraposición a la educación tradicional, que persigue evitarlo o anularlo. En la perspectiva tradicional, cuando los conflictos surgen, ni se tratan, ni se solucionan, pero se castigan, dando a entender que la disciplina se considera como un fin. En la pedagogía del conflicto, este se asume y se entiende como eje de la convivencia, es decir, es la base para la discusión y la promoción de formas no violentas de abordarlo. La disciplina es un medio para la convivencia. Es importante recalcar que la mediación y la resolución no violenta de conflictos debe ser el medio para la convivencia entre todos los actores y sectores de la comunidad escolar.

- Participación democrática: una escuela promotora de derechos y convivencia pacífica tiene que ser una escuela participativa 
que fomente la ampliación progresiva de la autonomía de los estudiantes.

De acuerdo con Hicks (1999), la educación para la paz es un intento de responder a los problemas de conflicto y de violencia que caracterizan lo que Galtung (1985, citado en Jares, 1999) denomina violencia personal o directa, y violencia estructural e indirecta. La educación para la paz propone modelos didácticos basados en el conflicto, como estrategia de aprendizaje en el marco de la denominada ciudadanía global: es un esfuerzo para consolidar una nueva manera de ver, entender y vivir el mundo. En palabras de Mesa (2001), la educación para la paz construye redes horizontales a partir de la confianza, la seguridad y la autoridad con las demás personas y con las sociedades, donde se intercambian experiencias de forma mutua, y se superan las desconfianzas, ayudando a movilizarlas y a superar las diferencias.

En ese sentido, la educación para la paz promueve el multiculturalismo, el conocimiento de la diversidad social y cultural desde su propia percepción y referentes, y cuestiona al racismo, la xenofobia, los valores y el modelo de desarrollo que generan pobreza y exclusión y favorecen el conocimiento crítico de los problemas globales como el medio ambiente, el armamentismo y las migraciones (Mesa, 2001).

$\mathrm{Al}$ respecto, Jares (1999) propone las siguientes características pedagógicas de la educación para la paz:

- La educación para la paz forma parte de lo denominado "educación en valores". La educación para la paz no solo es un hecho de paz, es una actividad política destinada a mejorar la comprensión del mundo de los individuos.

- Las investigaciones sobre la paz tienen una orientación sistémica, holística e interdisciplinar.

- La educación para la paz se integra de manera orgánica con la investigación y las acciones de paz.

- La educación para la paz se orienta hacia la acción y el cambio social. 
- La educación para la paz es realista y posible.

- La educación para la paz responde a las demandas del entorno en que se ejecuta.

- Se integra al currículum como uno de los ejes vertebrales de una práctica educativa crítica y emancipadora.

- Se asienta en el juego y en la risa, en lugar de la conquista y la seriedad.

- Educar para la paz significa educar para el manejo de los conflictos de forma no violenta, en el marco de una tolerancia de la diversidad y una potenciación de la autoestima.

De acuerdo con lo anterior se evidencian cinco enfoques característicos de la educación para la paz (Hicks, 1999):

- Educación para la paz a través de la fuerza: este enfoque es el respaldado por gobiernos y fuerzas armadas que consideran el mantenimiento de la paz mediante la disuasión armada.

- Educación para la paz como mediación y solución de conflictos: se centra en el análisis del conflicto, desde el personal al global, y en las maneras de resolverlo sin violencia.

- Educación para la paz como orden personal: de carácter interpersonal, subraya la necesidad de la empatía y la cooperación como formas de transformar las estructuras jerárquicas.

- Educación para la paz como orden mundial: parte de la necesidad de una perspectiva global y del reconocimiento de la violencia estructural como gran obstáculo para la paz.

- Educación para la paz como la abolición de las relaciones de poder: considera los valores de las personas como un producto de ciertas variables estructurales relacionadas con el poder económico, político y cultural. 
En el mismo texto, Hicks (1999) define tres presupuestos que permiten abordar los estudios sobre educación para la paz: el primero asume la guerra y el conflicto violento como factores que impiden el bienestar humano; el segundo considera que la violencia no es el resultado inevitable de la naturaleza humana; tercero, la paz es susceptible de aprenderse, ya que existen modos alternativos de ser, comportarse y organizarse. En este mismo ámbito, Hicks sugiere examinar el papel de las ideologías educativas:

- La tradición liberal humanitaria orientada a la transmisión de la herencia cultural.

- La tradición centrada en el niño, que considera la armonía social, la autonomía, la confianza en sí mismo y el autodesarrollo, como principios rectores de la educación.

- La tradición utilitaria.

- La tradición reconstruccionista, que considera a la educación como un instrumento potencial para el cambio social.

\section{¿Por qué hablar de convivencia y paz en el contexto colombiano?}

El conflicto armado en Colombia en los últimos sesenta años ha dejado la cifra aterradora de más de ocho millones de víctimas directas, y sembrado en lo más profundo del imaginario nacional "una máquina de guerra” en la cual, desde todas las esferas sociales, hay un señalamiento al diferente y una estigmatización al pensamiento divergente y plural.

Los niños colombianos en las últimas décadas han crecido en medio del estertor de la violencia armada y del flujo criminal de dineros ilícitos. Para un futuro ciudadano los problemas se resuelven a bala y por las malas, y todo se puede hacer con influencias, con plata y con armas. La famosa frase de "usted no sabe quién soy yo" opera en este imaginario social como parte del lenguaje corriente, a manera de actitud y de respuesta para solucionar cualquier infracción por grande que esta sea. 
En este marco general las víctimas de esta barbarie nacional resisten, sobreviven, reconstruyen sus dolores y sus vidas y perdonan. Los ejemplos a nivel nacional son numerosos: campesinos humildes, indígenas indefensos, poblaciones empobrecidas por el asedio de la guerra, dijeron no a los violentos y los enfrentaron sin armas distintas a su convicción de impedir que sus niños, niñas, jóvenes y mujeres, continuaran inundando los cementerios y los ejércitos de sangre de las filas paramilitares y guerrilleras.

Por lo general, estas resistencias se construyeron desde el clamor popular con un contundente "no" a los violentos. Se organizaron en comunidades de paz, donde, incluso, las fuerzas militares del Estado no podían portar armas. Narra el informe "Basta ya" del Centro de Memoria Histórica que:

Los intentos por cambiar la voluntad de los actores armados no siempre fueron exitosos. Su registro en la memoria sin embargo exalta los recursos a la palabra, las negociaciones cara a cara y los intentos valerosos que muchos hombres y mujeres emprendieron en situaciones extremas para liberar a sus seres queridos de un destino fatal. Estos actos son extraordinarios y constituyen formas de resistencia civil. Por ejemplo, en el año 2000 los paramilitares reclutaron algunos de los jóvenes de la comunidad del Valle Encantado en Córdoba mediante engaños y ofertas de empleo en fincas. (Centro Nacional de Memoria Histórica, 2013, pp. 81-82)

En el reciente debate sobre el plebiscito para que los colombianos refrendaran los acuerdos de paz entre el Gobierno Nacional y la guerrilla de las FARC, las víctimas del conflicto armado volvieron a dar ejemplo. Miles de ellos salieron a apoyar el acuerdo y muchas asociaciones constituyen hoy en día la muestra clara de cómo es posible no solamente perdonar, sino definir una hoja de ruta para resistir, sobrevivir y reconstruir, en medio de la polarización de un país que aún no tiene claro el valor de una paz estable y duradera. En ese contexto, emergió el valioso papel de la juventud colombiana, que sentó una posición y alzó su voz para exigir al Gobierno buscar una salida negociada a la fallida refrendación. Han 
sido múltiples los movimientos sociales de jóvenes, en su mayoría universitarios, que se han abanderado de la defensa del derecho a la paz en el país, y es justamente ello una razón para estudiar cómo se configura el desarrollo de esas competencias ciudadanas en las aulas.

\section{La paz como práctica de aula y cultura institucional}

Aunque intentar deslindar estos dos fenómenos es casi imposible, dadas las delgadas fronteras que diferencian estos dos aspectos, vale la pena tener en cuenta algunas consideraciones ya planteadas líneas atrás y que se cruzan alrededor de la paz como ausencia de conflictos o como la existencia de equidad e igualdad para lograr una verdadera convivencia.

Kattermann y Aramayo (2011) plantean en su trabajo el tema de la paz como un proceso al que denominan cultura de paz, el cual "se basa en valores, actitudes, comportamientos y estilos de vida que refuerzan la no violencia y el respeto de los derechos y libertades fundamentales de cada persona". En su propuesta, añaden que "ella depende de la observancia y aceptación del derecho de las personas a ser diferentes y de su derecho a una existencia pacífica y segura dentro de sus comunidades" (p. 16).

Estos autores toman como punto de referencia lo expuesto en el debate del Consejo Ejecutivo de la Unesco cuando el programa Cultura de Paz se presentó por primera vez en 1992:

[...] los conflictos son inevitables, necesarios y pueden incluso ser beneficiosos al suscitar la innovación, la actividad, la identidad y la reflexión. Pero los beneficios dependerán de nuestra capacidad para manejar los conflictos, para resolverlos equitativamente e impedir sus manifestaciones violentas destructivas. (p. 16)

Estos investigadores plantearon el desarrollo de mecanismos institucionalizados para el tratamiento de los conflictos en el ámbito escolar y la construcción de convivencia pacífica en el Sistema Educativo Boliviano, sustentados en dos premisas: 
La primera como Cultura de Paz en el proceso escolar, subcategorizadas a su vez como práctica de aula, por un lado, y como parte de la cultura institucional, por el otro. La segunda premisa, como Cultura de Paz desde la práctica cotidiana, la cual se sustenta en saberes y conocimientos, sobre la forma de analizar y comprender la realidad como requisito para transformarla, capacidades y habilidades, para gestionar los conflictos a través del diálogo y de mecanismos no violentos, y acción política y práctica de valores, entendidas como la toma de posición frente a la violencia, injusticia y otros. (p. 16)

Sobre esta misma postura de la cultura de paz, García (1998) también había hecho sus aportes cuando consideró que "para crear una cultura de paz una tarea esencial es reorientar el aprendizaje y los procesos de socialización que sostienen la infraestructura psicológica de la violencia”, según lo planteado por Alzate (citado en García, 1998, p. 2).

García agrega que "mientras las culturas de violencia transmiten odio, la opresión de generación en generación, la cultura de paz cultiva la cooperación y la interdependencia: valores de igualdad, diversidad, justicia social y salud económica". Y subraya que, "también cultiva normas, creencias y actitudes que apoyen la resolución de conflictos no violenta y la reconciliación. Aporta procesos de compromiso activos y realización espiritual que conduzcan a un cambio social positivo" (p. 2).

William Kreider (citado en García, 1998) acunó el término de "aula pacífica” en la década del setenta. Este autor propuso que

[...] para la consecución de todo esto proponemos caminar hacia la construcción de una escuela pacífica que descansa en varios principios que el profesor ha de cuidar mucho: y, entre otros, ofrecemos: primero, "desarmar la historia” segundo, "expresión positiva de las emociones" y tercero "resolución de conflictos".

Sobre este punto, Arellano (2007), por ejemplo, considera que:

Es un hecho que la violencia está en las escuelas y que tiene dos vertientes, una estructural que se manifiesta en la exclusión de la 
población de niños y adolescentes de un proceso educativo que brinde una calidad de vida, y una violencia directa que, se manifiesta en la destrucción de las instalaciones, educativa, de los bienes del docente. (p. 42)

Arellano (2007) deposita en el docente una alta responsabilidad en su función al afirmar que el "docente no está modelando el carácter social del educando para formarlo como un ciudadano que practique los valores de convivencia y que ejerza su autonomía con respeto por el otro". La autora piensa que este hecho termina "incidiendo esto en la generación de una violencia directa, que como se ha planteado, está presente en las instituciones educativas y en su contexto". La autora, concluye "que existe la urgente necesidad de transformar al docente y al alumno (...), donde se tenga como meta aprender a vivir juntos” (p. 42).

La óptica desde la cual se desarrolló la interpretación de este apartado en la investigación en competencias ciudadanas se sustentó en la paz como cultura, según Kattermann y Aramayo (2011). Tal cultura de paz se basa en valores, actitudes, comportamientos y estilos de vida que refuerzan la no violencia y el respeto de los derechos y libertades fundamentales de cada persona y ella depende de la observancia y aceptación del derecho de las personas a ser diferentes y de su derecho a una existencia pacífica y segura dentro de sus comunidades.

Este fenómeno debe ser entendido como una cultura de paz en el proceso escolar, en el cual se subcategorizan a su vez como práctica de aula, por un lado, y como parte de la cultura institucional, por el otro. La segunda premisa, como cultura de paz desde la práctica cotidiana, se sustenta en saberes y conocimientos sobre la forma de analizar y comprender la realidad como requisito para transformarla, capacidades y habilidades para gestionar los conflictos a través del diálogo y de mecanismos no violentos, y acción política y práctica de valores, entendidas como la toma de posición frente a la violencia, injusticia y otros. 


\section{¿Cómo se relacionan la convivencia y la paz?}

Esta es una mirada desde la resolución constructiva de conflictos. Dado que el estudio está ubicado en el contexto colombiano, es apenas obvio tener en cuenta la forma como el Estado ha organizado el Sistema de Educación para la Ciudadanía en este país. Por ello es importante conocer la posición del Ministerio de Educación al señalar que "la educación es uno de los caminos que hará posible la paz”. Para el Estado, "la convivencia y la paz se basan en la consideración de los demás y, especialmente, en la consideración de cada persona como ser humano" (MEN, 2004, p. 12).

Estos referentes están cimentados en las investigaciones de Chaux et al. (2004) cuando definen que "un ciudadano competente debe ser capaz de convivir con los demás de manera pacífica y constructiva”. Tales autores agregan que "esta convivencia no implica la armonía perfecta o la ausencia de conflictos". Los autores además sostienen que “esa perfección no es realista y tal vez ni siquiera sea deseable" (p. 19).

En este sentido, Galtung (citado en Chaux et al., 2004) opina que "mientras paz negativa se refiere a la ausencia de enfrentamientos violentos, paz positiva se refiere a la presencia de equidad e inclusión social" (p. 19). Galtung sugiere que los países deben buscar ambos tipos de paz.

Sin embargo, es necesario observar otros puntos de vista que ayuden a precisar la comprensión de los fenómenos de convivencia. DíazAguado (2001) dice que "para mejorar la convivencia educativa y prevenir la violencia es preciso enseñar a resolver conflictos (incluidos los relacionados con procedimientos de disciplina) de forma constructiva (...) y creando contextos normalizados, como las asambleas de aula" (p. 115).

Díaz-Aguado explica que "estudios realizados con adolescentes y adultos que recurren con frecuencia a la violencia reflejan que suelen tener dificultades para resolver de forma inteligente los conflictos y tensiones que experimentan". A razón de ello, es imperioso "ayudarles a descubrirlo y enseñarles procedimientos sistemáticos para resolver de 
forma más inteligente y justa sus tensiones y conflictos", lo que "puede ser, por tanto, un procedimiento muy eficaz para prevenir la violencia" (p. 118).

Otro elemento que confluye en esta serie de planteamientos es el de Jares (2002). Este autor sostiene que "aprender a convivir significa conjugar la relación de igualdad y diferencia”. Jares (1999b) dice que "las personas también somos diferentes por diferentes motivos y circunstancias; diferencias que pueden ser positivas y fomentadas y en otros casos diferencias que son negativas y por lo tanto deben ser eliminadas" (p. 118).

Gimeno (citado en Jares, 2002) piensa que "los seres humanos son desiguales o diferentes en muchas cosas que los jerarquizan entre sí. Eso es diferente en ciertos casos, positivo en algunos e inaceptable desde un punto de vista ético de otro" (p. 118). Y agrega que:

En cualquier caso, la diferencia o diversidad forma parte de la vida y puede ser un factor de conflictividad. Convivir en un ecosistema humano implica una disposición sensible a reconocer la diferencia, asumiendo con ternura las ocasiones que nos brinda el conflicto para alimentar el mutuo crecimiento. (Restrepo, citado en Jares, 2002, p. 86)

Jares añade que "es evidente que uno de los grandes conflictos que se plantean en la actualidad es la relación igualdad-diferencia". Considera que "desde los presupuestos de un educación democrática y comprometida con los valores de la justicia, la paz y los derechos humanos tenemos que afrontar esta diversidad afrontando los apoyos que sean necesarios". Sin embargo, aclara que "en ningún modo favoreciendo políticas de segregación en el interior de los propios centros” (p. 86).

Dados estos referentes teóricos se puede inferir que para construir una convivencia sana es "fundamental partir de la aceptación de que el conflicto es inevitable, porque solamente cuando se enfrentan y aprovechan las tenciones y confrontaciones propias del convivir es posible instaurar procesos de construcciones de una comunidad escolar pacífica" (Coronado, 2008b, p. 12). 
De tal modo que se asumirá en la actual investigación la perspectiva de Chaux et al. (2004), quienes sostienen que un ciudadano competente debe ser capaz de convivir con los demás de manera pacífica y constructiva, lo que no implica la armonía perfecta o la ausencia de conflictos; incluso esa perfección no es realista y tal vez ni siquiera sea deseable. Se entenderá desde el planteamiento de Díaz-Aguado (2001) que para mejorar la convivencia educativa y prevenir la violencia es preciso enseñar a resolver conflictos de forma constructiva y creando contextos normalizados, como las asambleas de aula, entre otras estrategias. Asimismo, se entenderá, como propone Restrepo (citado en Jares, 2002), que convivir en un ecosistema humano implica una disposición sensible a reconocer la diferencia, asumiendo con ternura las ocasiones que nos brinda el conflicto para alimentar el mutuo crecimiento. 
